\title{
Publication During the COVID-19 Pandemic
}

\author{
Victoria Williams MPH, CIC, Editor-in-Chief \\ Devon Metcalf MSc, PhD, CIC, Associate Editor
}

The appearance of a new disease, such as the COVID-19 pandemic, brings with it a rapid increase in the volume of information and research available, and the evolution of policies and practices. While information learned and tools developed can be shared informally among peers, the wider dissemination of information requires publication. In order to facilitate this process, the Wellcome Trust issued a statement in January 2020, which has since been signed by numerous international journals, publishers, professional organizations and societies, funding organizations, academic institutions, corporations and government agencies [1]. They called upon "researchers, journals and funders to ensure that research findings and data relevant to this outbreak are shared rapidly and openly to inform the public health response and help save lives". This would be accomplished by making peer-reviewed research publications freely available for the duration of the pandemic at a minimum, and potentially longer. Interim research findings would also be made available before journal publication. Many journals have created COVID-19 resource centres or content archives where publications related to the pandemic can be accessed and the World Health Organization has created a global research database that is updated daily with currently international and multilingual scientific literature [2]. The COVID-19 Open Research Database (CORD-19), a free resource created by the Semantic Scholar team at the Allen Institute for $\mathrm{Al}$, includes more than 100,000 articles about COVID-19 [3].

Although increased and fast-paced access to research findings has myriad benefits for the scientific community, there are some disadvantages. As the number of submissions increases and the time from receipt to final publication is shortened, the formal process of peer review may suffer. Peer-review involves having experts in the field evaluate a publication and serves two purposes. One, it ensures that published research is of a high quality by reviewing its validity, significance and originality. Two, it improves the quality of the manuscript by providing suggestions to the authors and identifying any errors [4]. Generally, this process from submission to publication takes months, but has been shortened to days and weeks for online publication of COVID-19-related articles. One study comparing the length of the publication process for 14 different journals during and prior to the COVID-19 pandemic found an average decrease in the turnaround time of $49 \%$ for COVID-19related manuscripts, but no change for articles not related to COVID-19 [5].

Many authors have also taken to publishing studies online prior to peer review, preprint publication, which raises the concern that findings are made available to the public prior to review and verification [6,7]. For example, in March 2020, an article on the use of hydroxychloroquine in COVID-19 patients was published online and subsequently the International Society of Antimicrobial Chemotherapy, the journal's sponsoring organization, released a statement agreeing with the concerns raised about the article's findings [8,9]. Similarly, the Lancet and New England Journal of Medicine retracted articles as data could not be verified $[10,11]$.

The large number of submissions and fast turnaround time also has human resource implications. Editors, editorial board members and reviewers are also researchers, clinicians, and frontline healthcare workers who have seen their workloads and commitments increase such that they are not available to commit to the time required to assist in the peer review and publication process [6]. The pace at which editorial board members need to provide reviews is likely unsustainable in the long term. As a result, the future of scientific publication may be permanently changed. The benefits of open and fast publications have been recognized as critically important for efficient communication and knowledge sharing in the face of a new infectious disease. Pre-prints, and all of the potential risks of no prior peer review that comes with them, do improve coordination and timely dissemination of research, and may continue to play a role beyond this pandemic [12]. The peer-review process itself might change to accommodate the necessary and expected fast turnaround time. Journals may incorporate new strategies, such as opting to review methodology prior to submission of a full manuscript to ensure the methodology is valid early on, or reviewers could share their feedback with authors in real time allowing corrections to be made before all of the reviews have been completed [6]. Regardless of how the process of scientific publications evolves, the need for validated research and thorough peer review by qualified reviewers won't change.

It is also worth noting that the pandemic has had a disproportionate effect on the authorship of women compared to their male counterparts. In reviewing COVID-19-related studies published in March and April, one study identified a $19 \%$ reduction in articles with a woman first author compared to papers published in 2019 in the same journals [13]. Others have reported similar findings [14]. One can only hope that as the pandemic evolves, worklife balances can be restored and this disparity can be resolved.

There is also a risk that COVID-19related research will overshadow other 
important research in the frenzy to produce and publish relevant and timely work to aid in the pandemic response. When time permits, it is important to revisit the work that was submitted as abstracts to cancelled conferences, such as IPAC Canada and APIC and consider publication. The issues, research and interventions that inspired these submissions remain vital to IPAC practice and need to be shared with our peers.

We would like to express our appreciation to the members of the editorial board who, despite increased workloads and demands on their time, have honoured their commitment to CJIC. Thank you to the external reviewers who graciously volunteered their time and skills in peer review. And finally, thank you to the authors for your ongoing submissions and for allowing us to disseminate your work to the infection prevention and control community, whether related to COVID-19 or otherwise.

\section{REFERENCES}

1. Wellcome Trust. Sharing research data and findings relevant to the novel coronavirus (COVID-19) outbreak. January 2020. Retrieved from https://wellcome.ac.uk/ coronavirus-covid-19/open-data. (Accessed June 7, 2020).

2. World Health Organization. COVID19: Global literature on coronavirus disease. Retrieved from https:// search.bvsalud.org/global-literatureon-novel-coronavirus-2019-ncov/. (Accessed June 7, 2020).

3. Semantic Scholar. CORD-19: COVID-19 Open Research Database. Retrieved from https:// www.semanticscholar.org/cord19. (Accessed June 7, 2020)
4. Kelly, J. Sadeghieh T, Adeli K. (2014). Peer review in scientific publications: benefits, critiques and a survival guide. EJIFCC, 25(3),227-243.

5. Horbach SPJM. Pandemic Publishing: medical journals drastically speed up their publication process for COVID19.(pre-print). Retrieved from https:// www.biorxiv.org/content/10.1101/2 020.04.18.045963v1.full. (Accessed June 14, 2020)

6. Kurth T, Piccininni M, Loder EW, Rohmann JL. A parallel pandemic: the crush of COVID-19 publications tests the capacity of scientific publishing. The BMJ Opinion. May 2020. Retrieved from https:// blogs.bmj.com/bmj/2020/05/26/aparallel-pandemic-the-crush-ofcovid-19-publications-tests-thecapacity-of-scientific-publishing/. (Accessed June 7, 2020)

7. Steinberg I. Coronavirus research done too fast is testing publishing safeguards, bad science is getting through. The Conversation.

2020. Retrieved from http:// theconversation.com/coronavirusresearch-done-too-fast-is-testingpublishing-safeguards-bad-scienceis-getting-through-134653. (Accessed June 7 2020).

8. Gautret $P$, Lagier JC, Parola $P$, Hoang VT, Meddeb L, Mailhe M, et al. (2020). Hydroxychloroquine and azithromycin as a treatment of COVID-19: results of an openlabel non-randomized clinical trial. International Journal of Antimicrobial Agents, ahead of print. doi: 10.1016/j.ijantimicag.2020.105949.

9. International Society of Antimicrobial Chemotherapy. Statement on IJAA paper. April 3, 2020. Retrieved from https://www.isac.world/news-andpublications/official-isac-statement. (Accessed June 7, 2020)

10. Mehra MR, Ruschitzka F, Patel AN. Retraction: Hydroxychloroquine or chloroquine with or without a macrolide for treatment of COVID19: a multinational registry analysis. DOI_10.1016/S0140-6736(2)313246. Lancet. June 5, 2020. Retrieved from https://www.thelancet.com/ journals/lancet/article/PIIS01406736(20)31324-6/fulltext. (Accessed June 7, 2020)

11. Mehra MR, Desai SS, Kuy S, Henry TD, Patel AN. Retraction: Cardiovascular Disease, Drug Therapy, and Mortality in Covid19. N Engl J Med. DOI: 10.1056/ NEJMoa2007621. NEJM. June 4, 2020. Retrieved from https:// www.nejm.org/doi/full/10.1056/ NEJMc2021225?query $=$ featured home. (Accessed June 7, 2020)

12. Kubota Y. Stanford researchers discuss the benefits - and perils - of science without peer review. Stanford News. April 6, 2020. Retrieved from https:// news.stanford.edu/2020/04/06/openscience-era-covid-19/ . (Accessed on June 15, 2020).

13. 13. Anderson JP, Neilsen MW, Simone NL, Lewis RE, Jagsi R. (2020). Meta-Research: COVID19 medical papers have fewer women first authors than expected. Elife, 15(9),e58807. doi: 10.7554/ eLife.58807

14. Viglione G. Are women publishing less during the pandemic? Here's what the data say. Nature News. 20 May 2020. Retrieved from https://www.nature. com/articles/d41586-020-01294-9. (Accessed on June 16, 2020). 